\title{
Energy recovery from Municipal Solid Waste in EU: proposals to assess the management performance under a circular economy perspective
}

\author{
Elena Cristina Rada $^{1, *}$, Lucian-Ionel Cioca $^{2}$, and Gabriela Ionescu ${ }^{3}$ \\ ${ }^{1}$ DICAM, University of Trento, Trento, Italy, \& DIIM, University Lucian Blaga of Sibiu, Sibiu, \\ Romania \\ ${ }^{2}$ DIIM, Lucian Blaga University of Sibiu, Sibiu, Romania \\ ${ }^{3}$ DPUE, Politehnica University of Bucharest, Bucharest, Romania
}

\begin{abstract}
In 2015 the European Commission issued a package of documents on Circular Economy concerning an integrated revision of legislative proposals on waste management. The aim was to stimulate a European transition towards a circular economy concept, which is expected to foster competitiveness, sustainable economic growth and new jobs generation. Three indicators are proposed in this paper to contribute to the assessment of the energy recovery management performance from MSW in a scenario of circular economy: a) referring to MSW directly used (RMSW) or indirectly used (SRF) as input of thermochemical plants, an indicator can be the percentage of waste having $\mathrm{LHV}>13 \mathrm{MJ} / \mathrm{kg}$; b) referring to the MSW directly or indirectly used as input of thermochemical plants, the percentage of waste having ash recovered; c) referring to food waste, percentage of this stream sent to anaerobic digestion. The above indicators, proposed and discussed in this paper, have to be integrated with other ones in order to complete the quantification of the role of MSW management in term of energy recovery under a circular economy strategy. It is not the aim of the present paper to give a comprehensive solution to this complex issue.
\end{abstract}

\section{Introduction}

Currently, world cities generate about 1.3-1.9 billion tonnes of solid waste per year. This volume is expected to increase to 2.2 billion tonnes by 2025 . Globally solid waste management costs will increase from today's annual 205.4 billion $\$$ to about 375.5 billion $\$$ in 2025 [1]. Worldwide, of the MSW collected, 19\% is recycled, $11 \%$ is used in energy recovery and the rest ends up in landfills or dumps [2]. In this context, there is a stringent need for the development and implementation of sustainable sociotechnical systems. Since 1975, when the European Union (EU) first introduced its waste hierarchy, our society has been undergoing to a transition process, from only manufacturing and production activities to a systematic and environmental thinking [3-4]. In the last decades, the linear 'take-make-

*Corresponding author: elena.rada@,unitn.it 
use-dispose' economy approach has been used, relying on the production of large quantities of low-cost, easily accessible material and energy, a model that has reached-up to the end of the line, due to its many environmental challenges: the resource depletion, waste generation and emissions [5-6]. The sustainability role is to address economic, social and environmental issues of present and future generations, in the perspective of a balanced and systemic integration of intra and intergenerational economic, social, and environmental performance [7]. To overcome the environmental challenges of the conventional linear economy model and moving towards sustainability, the concept of Circular Economy (CE) has become one of the most modern approaches to address economic growth and environmental sustainability, aiming to the implementation of closed loop material flow in the whole economic system [8]. In line with the $3 \mathrm{R}$ of the environment, the CE relays on the circular material flow involving recovery, reuse, recycling and remanufacturing of products and the use of raw materials and energy through multiple phases $[9,10]$.

In the light of the above mention, in 2015 the European Commission proposed a set of recommendations on the current waste legislations linked with CE. The official aim is "to stimulate Europe's transition towards a circular economy which will boost global competitiveness, foster sustainable economic growth and generate new jobs" [11]. The EU programme of action contains measures involving the whole cycle: "from production and consumption to waste management and the market for secondary raw materials" [11]. The common action plan proposed by the EU for CE, considers specific key targets for all the member states such as: to reach up to a recycling common target of $65 \%$ of municipal waste and $75 \%$ of packaging waste by 2030 ; to reduce landfill to maximum of $10 \%$ of municipal waste by 2030; to prohibit landfilling of separately collected waste through the promotion of economic tools; to have clear and simplified definitions, methods and standards for recycling rates all over EU; to have concrete forms that promote the close-loop of the re-use material option; to stimulate EU towards a sustainable market place by offering greener products and service programs that support recovery and recycling systems.

If we consider the CE a priority in the EU waste management, the above mentioned "package" underlines the importance of reuse and recycling before energy recovery. The target indeed is to close the loop of product lifecycles by an increase and an optimization of and re-use. It is important to point out that this target is seen also in terms of favorable balances for both the environment and the economy.

In this paper, the effects of material recovery maximization are discussed in terms of effects on the strategies of energy recovery.

\section{Role of energy recovery from MSW in a frame of material recovery maximisation}

At the moment the linear economy is being gradually replaced by the CE that aims towards a zero waste framework [12-16] The main factors that are underlying the bases of any sustainable waste management are the reliable and up-to-date information and their trends regarding the quantitative and qualitative characteristics of the MSW stream, considering the demographic changes, the socio-economic and technological maturity, environmental policies, decision-makers and the interests of the parties involved in the process [17-19]. The most advanced and sustainable, Integrated Municipal Solid Waste Management Systems must maintain an equilibrium between the separately collected (SC) waste fractions and the Residual Municipal Solid Waste (RMSW), both of them being suitable for material and energy recovery. The environmental citizenship and waste services play an important role in the RMSW treatment options [20-21]. Furthermore, in some regions the political differences and unstable legislative framework can recede, obstruct or cause modifications from the original waste management plan, leading to the community confusion, slowing the 
implementation of the industrial recovery processes and usage of valuable secondary products that can be put on the market, delaying the environmental and economic impact.

The different waste collection systems (through containers- common or separate by waste fraction, door-to-door or drop-off collection) affect not only the quantity of the MSW stream collected but also its mass distribution. In these context, studies have identified three individuals' indicators [22-30]:

- The organic waste (green and biodegradable household waste) source separated;

- Packaging waste source separated: paper and cardboard, plastics, glass, metals (e.g. aluminium, iron), wood;

- RMSW (the mixed waste not source separated).

Therefore, the amount of MSW collected becomes a key variable in the development of sustainable waste management plans. The ideal theoretical scenario is to achieve complete $\mathrm{SC}$ of waste, by fractions, even thou this case seems to be impossible, which means that the RMSW is composed from both recyclable and non-recyclable materials, with or without energy potential. According the European Commission report (2015) on 'Separate collection schemes in the 28 capitals of the EU', the EU-28 average SC rate by capital reaches out to $18.5 \%$ [31]. The efficiency of MSW selective collection has successfully been registered in some EU regions, reaching out to $65.7 \%$ in 2011 and heading to $80 \%$ [32,33].

It is obvious that the increase of SC rate represents the decrease of the RMSW stream. In this sense the RMSW treatment options should be developed considering the above mentioned main factors that underline a sustainable waste management plan. Therefore, two aspects can be pointed out and are described below.

- The first one relates to the decreasing percentage of the organic fraction in the RMSW. This aspect is due on the one hand to the increase of the use of packaging, not always accompanied by an increase of selective collection of this fraction; on the other hand, the activation of organic fraction SC decreases its content in the RMSW. In the most extreme cases the percentage of organic fraction in RMSW may fall below $10 \%$. It may be pointed out that in Romania the MSW is mostly collected in an unselective manner, with no SC of the organic fraction and a poor SC of household Packaging Waste that covers a 23\% from total population, $46 \%$ in urban and $4 \%$ in rural areas [34-35].

- The second one is related to a fraction emerged recently, the diapers. Their use has grown significantly in some regions, also among the oldest people, and the absence of SC for this fraction makes their presence even more relevant in RMSW, where their percentage may reach today, in the extreme cases, even $20 \%$ and more if SC of other materials is high.

Considering the RMSW characteristics (mainly heating value, chlorine and mercury content) the waste stream could be defined potentially as Refused Derived Fuel (RDF) or Solid Recovered Fuel (SRF) apart from the need of homogeneity. The role of these fuels in the development of waste management in the CE frame will be discussed in the next section. The waste stream characteristics (mainly volatile solids, non-volatile solids, and water content, chlorine and mercury content) will dictate the selection of the available treatment options (combustion, gasification, pyrolysis, integrated thermal plants, aerobic/anaerobic mechanical-biological treatments etc., which have as main target energy recovery).

Waste to Energy is the predominant mass burning technology. In 2013, 520 plants were operational in Europe, treating around 95 million tons of MSW and commercial waste per year [36]. Incineration is a well-known option [37-38]. In conventional waste combustors the RMSW Lower Heating Value (LHV), in areas with high SC rate, is around $13.5 \mathrm{MJ} \mathrm{kg}^{-1} \mathrm{RMSW}$ with peaks of LHV expected during operation that can reach $20 \mathrm{MJ} \mathrm{kg}^{-1} \mathrm{RMSW}$ [39]. The energetic potential of the RMSW depends also of the organic fraction SC, that has a typically $70 \%$ water content, making this stream unsuitable for any thermal treatment. The high SC efficiency of the non-combustible fractions, decrease the slag formation during RMSW 
incineration. Over the years the improvement of the incineration operation conditions led to the reduction of the slag generation up to $20 \%$ from the initial waste stream flow treated on one hand and the volatile solids content on the other. Slag today can be converted into products for the building sector even through "cold" processes of sorting and grinding. The resulting material is included into concrete products for simplified uses. That is surely interesting from the circular economy point of view.

Anaerobic Digestion uses microorganisms to break down biodegradable material in absence of oxygen into methane and carbon dioxide. The resulted co-product is a nutrientrich digestate that can be used as fertilizer. The biogas can be used directly as fuel, in combined heat and power plants or treated in order to improve its quality and obtain biomethane. The correct SC of Organic Fraction of Municipal Solid Waste (OFMSW) stream plays an important role in the anaerobic process conditions and methane quantity and quality production. Wastes with higher lignocellulosic content present lower anaerobic biodegradability and extractable substances (soluble in water and alcohol) have a positive effect on methane production [40]. In Europe, 57\% of the organic wastes treated is for compost production to be used in agriculture, and the remaining $43 \%$ is used for biogas production under anaerobic conditions [41]. One of the innovative waste pre-treatments that increases the anaerobic digesters performances is electro-oxidation. The adoption of this approach as pre-treatment of waste must take into account the different lasting of the treatment (shorter for MSW and its fractions) [39]. Anaerobic digestion of OFMSW is followed by post-composting, making the approach interesting from the CE point of view.

Composting, an aerobic degradation, the organic fraction of MSW using aerobic microorganisms in the presence of oxygen. The aerobic process produces $\mathrm{CO} 2, \mathrm{H} 2 \mathrm{O}$, nitrates, sulfates and heat in addition to a stable solid material commonly used as fertilizer for agriculture crops [42-43]. The adoption of direct composting (that is without a pre-stage of anaerobic digestion) does not change the amount of compost produced.

Considering the latest results in the optimization of the anaerobic process, the option of producing both biomethane and compost (two products) must be preferable from the CR point of view.

For aerobic mechanical biological treatments, two methods can be used as pre-treatment of the RMSW: bio-drying (usually single stream) and bio-stabilization (double stream).

Biostabilization is adopted as pre-treatment before landfilling thus it seem not coherent with the CE principles [44]. Bio-drying belongs to the biological mechanical treatment options and is aimed to the dewatering of MSW thanks to the biological exothermal reactions (thermal drying, on the contrary, needs an external heat source as methane, in order to increase the lower heating value of the treated material) $[45,46]$. Particular, bio-drying, by reducing the water content of the waste, produces an increase in calorific value of about 30 $40 \%$ [47]. In practice, this process concentrates the initial energy content in a lower mass. A small energy loss (2\%-3\%) referred to the initial LHV characterizes this process. After a mechanical post-treatment the obtained material can used be re-used as fuel in thermal treatment plants. The possibility to extract recyclable materials and generate a product (SRF) makes bio-drying interesting from the CE point of view.

Gasification is the thermochemical conversion of the raw material (solid or liquid) in the presence of substoichiometric air/oxygen or water vapours, which converts volatile solids (VS) into a combustible gas (syngas). The syngas is mainly composed of carbon monoxide (CO) and hydrogen $\left(\mathrm{H}_{2}\right)$. In comparison with traditional waste incineration, gasification has some potential advantages: the syngas is suitable for different application (combustion in traditional burners, connected to a boiler and a steam turbine, gas reciprocating engines or gas turbines or its conversion in valuable products as chemicals and fuels due to $\mathrm{CO}$ and $\mathrm{H}_{2}$ content) [48]. This change of approach can give environmental advantages [49]. 
To this concern, the integrated systems based on the concept of coupling directly a gasification chamber and a combustor for syngas give three advantages:

- The possibility to better regulate the combustion as performed by a combustible gas (and not by a solid, as in the conventional combustion)

- The possibility to enhance the efficiency of the electricity generation from steam turbine thanks to lower problems of corrosion

- The possibility to vitrify the non volatile solids opening to solutions alternative to a landfill (coherently with CE)

Pyrolysis is a endothermic process, consisting of thermal decomposition of the material, in a free oxygen or air atmosphere, in order to obtain non-condensable gas products (such as $\mathrm{CO}, \mathrm{CO}_{2}, \mathrm{H}_{2}, \mathrm{CH}_{4}$ and other hydrocarbons), liquid products (oils, tars) and carbonaceous residue within inorganic solid particles (char). Pyrolysis gas has potential applications in the energy industry such as: a) direct use by its combustion to produce heat and/or electrical (via combustion spark-ignition engine or compression ignition); b) directly or with different fuel (e.g. coal) to produce individual gases including $\mathrm{H}_{2}, \mathrm{CH}_{4}$ or other volatile liquid fuels or biosynthetic. In some applications, the hot gases resulting from the pyrolysis process may be used in the process for preheating the reactor or inert gas [50-51]. Depending on its composition and additional treatments the pyrolysis oil can be used as unconventional fuel. Char is an attractive substitute for coal, due to increased energy potential [52]. Unfortunelly, essentially no commercial application on MSW or RSMW pyrolysis have been registred, due the limited operational conditions of the process, were a more homogenous input flow is preferable.

Considering the present analysis in the circular economy context, the aim of these options is to improve the environmental and energy balances compared to traditional approches and to obtain a valuable product as output. The possibility of having a product as output can be seen surely positive from the CE point of view.

\section{The role of Solid Recovered Fuel among the options of energy recovery for landfill minimisation}

The waste derived fuel can be classified as MSW by-product in case it meets certain classification standards, having more stable physical-chemical properties than the constituent raw material and markedly cheaper than primary fuels, becoming more attractive for the energy intensive industrial sectors such as cement industry, pulp and paper industry, thermal power plants [53].

In Europe, the mechanical/biological treatment (MBT) is an increasing option for the $\mathrm{RDF} / \mathrm{SRF}$ production for industrial purposes, but also as a pre-treatment before landfilling or as a pre-treatment before combustion in dedicated plants. The interest for this kind of treatment has become higher and higher not only in the old European Union (EU) members, but also in the recent entries, in order to comply with landfilling of biodegradable waste minimization. As already underlined, this scenario is not steady, as the EU Member States must introduce source-separation strategies that can affect the composition of the residual MSW to be treated in MBT plants.

The RDF is a fuel product, which has more uniform particle size distribution and higher energetic potential than untreated MSW. The main sources of organic and inorganic chlorine content in waste fractions are from $0.1 \mathrm{wt} . \%$ in wood to $>6 \mathrm{wt} . \%$ in non-packaging plastics (dry basis), polyvinylchloride (PVC) from packaging, electrical wire insulation etc. in plastics and chloride salts (mainly $\mathrm{NaCl}$ ) in kitchen waste [54]. In the WtE plants chlorine causes high temperature corrosion and low conversion efficiency. Zinc presence in the MSW seems to be in the range $3000-4000 \mathrm{mg} / \mathrm{kg}_{\mathrm{DS}}$ [55]. Zinc, lead and tin lower the melting temperature of deposits on the superheater tubes amplifying corrosion [56]. Trace and major 
elements affect the composition of ash [57].

There were only two RDF classes in Italy before 2010 (RDF and RDF_Q), depending mainly on the calorific value ( $>15$ and $20 \mathrm{MJ} / \mathrm{kg}_{\mathrm{RDF}}$ respectively), moisture $(<25 \%$ and $18 \%$ respectively) and ash content $(<20 \%$ and $15 \%$ respectively, referred to dry matter). Today there are 125 SRF classes, since 2010, based on limit values for three fuel properties:

a) the mean value for net calorific value (NCV; as received);

b) the mean value for chlorine content (dry basis);

c) the median and 80th percentile values for mercury content (as received) [58].

Therefore the RDF needs improvements and shifting to a high quality combustible fuel (SRF) that is covered by specific requirements in the legislations. In Italy, the classification of fuels from municipal solid waste (MSW) has changed in recent years with the introduction of 30 technical documents, mainly in the range of norms UNI CEN/TS 15357-15747, some of which have been operative since 2006. These documents set out all the characteristics, definitions, sampling methods, parameters of interest and analytical methods for SRF, while the previous term "Refuse Derived Fuel" (RDF) was not given by any legal definition and it was interpreted differently across countries [59].

Some new concepts have been introduced and other aspects are now more detailed; e.g. the quality management system concept for the production of SRF from the reception of waste(s) up to the delivery of SRF has now a specific norm, that requires data regarding source and origin of waste, information on waste production processes, data on the waste composition (main materials), appearance of waste, European Waste Code, chemical analysis when necessary; moreover, the sampling method of SRF from production plants, from deliveries or from stock in order to obtain the laboratory samples refers to 3 technical norms instead of one; the metals characterization is now more detailed for each element being represented by 3 technical norms, that cover a large number of parameters: $\mathrm{Al}, \mathrm{Ca}, \mathrm{Fe}, \mathrm{K}$, $\mathrm{Mg}, \mathrm{Na}, \mathrm{P}, \mathrm{Si}, \mathrm{Ti}, \mathrm{As}, \mathrm{Ba}, \mathrm{Be}, \mathrm{Cd}, \mathrm{Co}, \mathrm{Cr}, \mathrm{Cu}, \mathrm{Hg}, \mathrm{Mo}, \mathrm{Mn}, \mathrm{Ni}, \mathrm{Pb}, \mathrm{Sb}, \mathrm{Se}, \mathrm{Tl}, \mathrm{V}, \mathrm{Zn}$ and metallic aluminium; the precursors of acid gases are now analyzed in details; not only chlorine is taken into account but also sulphur $(\mathrm{S})$, chlorine $(\mathrm{Cl})$, fluorine, $(\mathrm{F})$ and bromine (Br); a specific technical norm concerns the assessment of the biomass content in SRF. This is an important aspect as related to some incentives.

Summing up, SRF seems to be an interesting product generated from RMSW (that should have only non-recyclable materials) in the frame of a CE concept.

\section{Preliminary proposals for assessing the energy recovery management performance}

Referring to MSW directly used (RMSW) or indirectly used (SRF) as input of thermochemical plants, an indicator of energy recovery management performance can be the percentage of waste having $\mathrm{LHV}>13 \mathrm{MJ} / \mathrm{kg}$. In a region the MSW stream sent to energy recovery by thermochemical plants could be differentiated in sub-streams depending on the final destination and the pre-treatment adopted (if any). In both cases it is important to verify if the threshold value proposed by the EU for addressing the energy strategies in the waste sector is taken into account or not.

Referring the MSW directly or indirectly used as input of thermochemical plants, another indicator can be the percentage of waste having ash recovered. Slag can be potentially used as a pozzolanic material in cement industry and fly-ash can be potentially vitrified and used as secondary product [60-61]. The indicator check if these opportunities are followed.

Referring food waste (from selective collection), a third indicator can be the percentage of this stream sent to anaerobic digestion. As discussed above, the option of anaerobic digestion gives two final products: biogas and compost. This should be preferable to direct composting. 


\section{Conclusions}

In the described frame, the sector of MSW management seems to be ready to comply with the principles of CE. What seems still potentially critical is the economic sustainability. From the circular economy point of view, the evolution of the sector of SRF, if based on nonrecyclable waste, can help to exploit industrial plants, like the cement factories ones, for integrating the ash of the input into a final product, without the need of a new complex thermochemical plant. Unfortunately, often SRF is not yet recognized as a product (a real fuel) that deserves to be bought. On the contrary who generates SRF could have to pay a fee for its exploitation (if a dedicate plant is not directly available). In spite of the present situation, the perspective of CE towards RMSW management seems to be clearly oriented to options characterised by a double output: energy generation and valorisation of the nonvolatile solids.

This work has been partly supported by University Politehnica of Bucharest, through the "Excellence Research Grants" Program, UPB - GEX. Identifier: UPB-EXCELENȚ Ă-2016, Research project title Asigurarea alimentării cu energie în regim continuu printr-un Sistem hibrid Integrat cu utilizarea Deșeurilor cu potențial energetic, surselor Eolione și Fotovoltaice/ Continuous power supply through an integrated hybrid system using wastes with high energetic content, photovoltaic and wind energy, Contract number: 90/26.09.2016 (acronym:SIDEF).

\section{References}

1. D. Hoornweg, P. Bhada-Tata. What a waste: a global review of solid waste management. (2012).

2. http://www.atlas.d-waste.com/ (2017)

3. M.E.B. Seiffert, C. Loch, J. Clean. Prod. 13(12), 1197-1202 (2005)

4. I.D. Williams, Waste Manage. 40, 1-2 (2015)

5. S. Huysman, J. De Schaepmeester, K. Ragaert, J. Dewulf, S. De Meester, Resour. Conserv. Recy. 120, 46-54 (2017)

6. D. Ness, Int. J. Sust. Dev. World Ecol. 15(4), 288-301 (2008).

7. M. Geissdoerfer, P. Savaget, N.M. Bocken, E.J. Hultink, J. Clean. Prod., 143, 757-768 (2017)

8. Y. Geng, B. Doberstein, Int. J. Sust. Dev. World. 15(3), 231-239 (2008)

9. Z. Yuan, J. Bi, Y. Moriguichi, J. Ind. Ecol. 10(1-2), 4-8 (2006)

10. I.S. Jawahir, R. Bradley. Procedia CIRP 40, 103-108, (2016)

11. http://ec.europa.eu/environment/circular-economy/, (2016)

12. R. Patrascu, E. Minciuc, D. Tutica, M. Norisor, G. Ionescu, P. Stefani. Quality - Access to Success 15(138), 84-88 (2014)

13. J.Y. Park, M.R. Chertow, J. Environ. Manage. 137, 45-53, (2014)

14. P. Ghisellini, C. Cialani, S. Ulgiat, J. Clean. Prod. 114, 11-32, (2016)

15. N.F. Cruz, P. Simões, R.C. Marques J. Clean. Prod. 37, 8-18, (2012)

16. E.C. Rada, M. Ragazzi., L.I. Cioca, G. Ionescu, E. Ranieri, E. Trulli, Quality - Access to Success 18, 151-156 (2017)

17. M. Ragazzi, V. Torretta, G. Ionescu, I.A. Istrate. WIT Transact. Ecol. Environ. 176, 235-244 (2013)

18. V. Torretta, G. Ionescu (2016). Manag. Enviro. Quality: An Int. J. 27(4), 419-426 (2016)

19. E.C. Rada, C. Bresciani, E. Girelli, M. Ragazzi, M. Schiavon, V. Torretta, Sustainability 8(9), 840 (2016)

20. A. Castagna, M. Casagranda, A. Zeni, E. Girelli, E.C. Rada, M. Ragazzi, T. Apstol, UPB Sci. Bull., serie D., 75(4), 253-264 (2013|)

21. Onyanta, Georg. Compass, 10(12), 499-513 (2012)

22. L. Rigamonti, I. Sterpi, M. Grosso Ecol. Indic. 60, 1-7 (2016)

23. E.C. Rada, M. Ragazzi, G. Ionescu, G. Merler, F. Moedinger, M. Raboni, V Torretta, Energ Procedia 50, 1037-1044 (2014)

24. S. Ciuta, T. Apostol, V. Rusu, Sustainability 7(1), 916-931 (2015)

25. F. Ferreira, C. Avelino, I. Bentes, C. Matos, C.A. Teixeira, Waste Manag. 59, 3-13 (2017) 
26. G. Ionescu, E.C. Rada, L.I. Cioca, Eviron. Eng. Manag. J. 14(11), 2537-2544 (2015)

27. S. Bungau, C. Bungau C, D.M. Tit, J. Environ. Prot. Ecol., 16(1), 56-62 (2015)

28. D.E. Popescu, C. Bungau, M. Prada, C. Domuta, S. Bungau, D.M. Tit, J. Environ. Prot. Ecol., 17(3), 1011-1020 (2016)

29. V. Torretta, E.C. Rada, M. Ragazzi, E. Trulli, I.A. Istrate, L.I. Cioca, Waste Manag., 45(SI), 152$160(2015)$

30. S. Bungău, R. Suciu, A. Bumbu, G. Cioca, D.M. Tit, J. Environ. Prot. Ecol., 16(3), 980-987 (2015)

31. European Commission report, Assessment of separate collection schemes in the 28 capitals of the EU. Reference: 070201/ENV/2014/691401/SFRA/A2 (2015)

32. M. Ragazzi, E.C. Rada, WIT Transact. Ecol. Environ. 109, 613-620 (2008)

33. R. Ciudin, C. Isarie, L.I. Cioca, V. Petrescu, V. Nederita, E. Ranieri, UPB Sci. Bull. serie D, 76(3), 215-222 (2014)

34. V. Petrescu, R. Ciudin, C. Isarie, V. Nederita, World Transact. Eng. Technol, Educ. 8(1), 107-110 (2010)

35. http://ec.europa.eu/environment/waste/framework/pdf/RO_factsheet_FINAL.pdf (2015)

36. https://waste-management-world.com/a/time-out-for-waste-to-energy-in-europe (2013)

37. U. Arena, F. Ardolino, F. Di Gregorio, Waste Manag. 41, 60-74 (2015)

38. R.L. Smith, D. Sengupta, S. Takkellapati, C.C. Lee, Resour. Recov. Conserv. 104, 311-316,(2015)

39. E.C. Rada, I.A. Istrate, M. Ragazzi, Environ. Technol. 30(7), 651-661 (2009)

40. R. Campuzano, S. González-Martín Waste Manag. (to be published)

41. F. Micolucci, M. Gottardo, C. Cavinato, P. Pavan, D. Bolzonella, Waste Manag. 48, 227-235 (2016)

42. G.C Fitzgerald, Waste to Energy Conversion Technology (2013)

43. M. Ragazzi, P. Tosi, E.C. Rada, V. Torretta, M. Schiavon, Waste Manag. 34(11), 2400-2406 (2014)

44. S. Ciuta, S. Antognoni, E.C. Rada, M. Ragazzi, A. Badea, L.I. Cioca. Sustainability 8(12), 1311 (2016)

45. E.C. Rada, A. Franzinelli, M. Ragazzi, V. Panaitescu, T. Apostol, Chemosphere 68(9), 1669 -1674 (2007)

46. M. Ragazzi., E.C. Rada, D. Antolini. Waste Manag. 31(9-10), 2085-2091 (2011)

47. F. Adani, D. Baido, E. Calcaterra, P. Genevini, Bioresour. Technol. 83(3), 173-179 (2002)

48. U. Arena, Waste Manag. 32(4), 625-639 (2012)

49. C. Marculescu, Energ. Procedia 6, 558-564 (2011)

50. O. Bičáková, P. Straka, Int. J. Hydrogen Energ. 37(16), 11536-11578 (2012)

51. C. Marculescu, I. Minca, F. Bacalum, Rev Chim. 66(11), 1837-1840 (2015)

52. A. Demirbas, J. Anal. Appl. Pyrol. 72(1), 97-102 (2004)

53. E. Kakaras, P. Grammelis, M. Agraniotis, W. Derichs, H.P. Schiffer, J. Maier, T. Hilber, T. Glorius, U. Becker, Therm. Sci. J. 9(2), 17-30 (2005)

54. W. Ma, G. Hoffmann, M. Schirmer, G. Chen, V.S. Rotter, J. Hazard. Mater. 178(1-3), 489-498 (2010)

55. F. Jones, D. Bankiewicz, M. Hupa, Fuel 117(A), 763-775 (2014)

56. B. Gawlik, E. Sobiecka, S. Vaccaro, G. Ciceri, Energ. Policy 35(12), 6293-6298 (2007)

57. M. Nasrullah, P. Vainikka, J. Hannula, M. Hurme, Fuel 145, 1-11 (2015)

58. E.C. Rada, G. Andreotolla, Waste Manag. 32(6), 1059-1060 (2012)

59. L. Lombardi, E. Carnevale, A. Corti. Waste Manag. 37, 26-44 (2015)

60. K.L. Lin, D.F. Lin, Cement Concrete Comp. 28(9), 817-823 (2006)

61. Y.J. Park, J. Heo, J. Hazard. Mater. 91(1), 83-93 (2002) 